\title{
Pseudophakic cystoid macular edema: update 2016
}

This article was published in the following Dove Press journal:

Clinical Interventions in Aging

9 September 2016

Number of times this article has been viewed

\author{
Andrzej Grzybowski ${ }^{1,2}$ \\ Bartosz L Sikorski ${ }^{3}$ \\ Francisco J Ascaso ${ }^{4,5}$ \\ Valentín Huerva ${ }^{6,7}$ \\ 'Department of Ophthalmology, \\ University of Warmia and Mazury, \\ Olsztyn, Poland; ${ }^{2}$ Department of \\ Ophthalmology, Poznań City Hospital, \\ Poznań, Poland; ${ }^{3}$ Department of \\ Ophthalmology, Nicolaus Copernicus \\ University, Bydgoszcz, Poland; \\ ${ }^{4}$ Department of Ophthalmology, \\ Hospital Clínico Universitario \\ "Lozano Blesa”, Zaragoza, Spain; \\ Instituto de Investigación Sanitaria \\ Aragón (IIS Aragón), Zaragoza, Spain; \\ ${ }^{6}$ Department of Ophthalmology, \\ Universitary Hospital Arnau de \\ Vilanova, Lleida, Spain; ${ }^{7}$ IRB Lleida, \\ Lleida, Spain
}

\begin{abstract}
Pseudophakic cystoid macular edema (PCME) is the most common complication of cataract surgery, leading in some cases to a decrease in vision. Although the pathogenesis of PCME is not completely understood, the contribution of postsurgical inflammation is generally accepted. Consequently, anti-inflammatory medicines, including steroids and nonsteroidal antiinflammatory drugs, have been postulated as having a role in both the prophylaxis and treatment of PCME. However, the lack of a uniformly accepted PCME definition, conflicting data on some risk factors, and the scarcity of studies comparing the role of nonsteroidal anti-inflammatory drugs to steroids in PCME prevention make the problem of PCME one of the puzzles of ophthalmology. This paper presents an updated review on the pathogenesis, risk factors, and use of anti-inflammatory drugs in PCME that reflect current research and practice.

Keywords: Pseudophakic cystoid macular edema, cataract surgery, cataract surgery complications, retina, post-operative complications
\end{abstract}

\section{Introduction}

Pseudophakic cystoid macular edema (PCME) is the most common complication of cataract surgery. Because of the heterogeneity of definitions and diagnostic criteria, its incidence has been reported to be between $1 \%$ and $30 \%$ (Table 1), with, however, an incidence of $1 \%-2 \%$ of clinically significant PCME in patients with no risk factors. Although in most cases, PCME is a self-limiting disorder; in rare cases, it can lead to long-term visual deterioration that is difficult to treat. Thus, it is important to discuss recent studies on PCME prevention and treatment measures, as well as the recommendations of major ophthalmic societies.

\section{Definition}

Different methods have been used to diagnose PCME. It has been determined from angiographic findings by fluorescein angiography, from clinical findings by fundoscopy, by deterioration in visual acuity, and from optical coherence tomography (OCT) findings of central subfield macular thickening. The incidence rates of PCME vary substantially according to the method of diagnosis (Table 1). ${ }^{1-11}$ Moreover, its incidence has decreased with less invasive and less traumatic cataract surgery techniques (Table 1). Thus, it is difficult to compare the incidence of PCME between studies that are based on different surgery techniques and different diagnostic techniques (Table 1).

\section{Pathogenesis}

Correspondence: Andrzej Grzybowski Department of Ophthalmology, Poznań City Hospital, Szwajcarska 3, Poznań 6I-285, Poland

Email ae.grzybowski@gmail.com
Although PCME was described many years ago, its pathophysiology remains uncertain and a multitude of mechanisms have been suggested. Various factors have been implicated in its development, including, but not limited to, inflammation, vascular instability, vitreomacular tractions, and light toxicity. ${ }^{12-14}$ Most researchers agree that 
Table I Incidence of PCME in different cataract extraction techniques in uncomplicated cataract operations

\begin{tabular}{llll}
\hline Cataract extraction technique & $\begin{array}{l}\text { Incidence of clinically } \\
\text { significant PCME }\end{array}$ & $\begin{array}{l}\text { Incidence of PCME } \\
\text { defined by FA }\end{array}$ & $\begin{array}{l}\text { Incidence of PCME } \\
\text { defined by OCT }\end{array}$ \\
\hline Intracapsular cataract extraction & $8 \% 1$ & $36 \%-60 \%^{5}$ & Not available \\
Extracapsular cataract extraction & $0.8 \%-20 \%^{2}$ & $16 \%-32.2 \%^{6,7}$ & Not available \\
Phacoemulsification & $0.1 \%-2.35 \%^{3}$ & $20 \%-54.7 \%^{8,9}$ & $3 \%-41 \%^{10,11}$ \\
Femtosecond-assisted cataract surgery & $1.18 \%^{4}$ & & $1.18 \%^{4}$ \\
\hline
\end{tabular}

Abbreviations: PCME, pseudophakic cystoid macular edema; FA, fluorescein angiography; OCT, optical coherent tomography.

postoperative inflammation seems to be a major cause of PCME. It is postulated that surgical manipulation within the anterior chamber may lead to the release of arachidonic acid from uveal tissue, with the production of either leukotrienes via the lipoxygenase pathway or prostaglandins (PGs) via the cyclooxygenase (COX) pathway. ${ }^{15}$ Subsequently, inflammatory mediators diffuse posteriorly into the vitreous and disrupt the blood-retinal barrier. This disruption results in increased permeability of the perifoveal capillaries and fluid accumulation within the retina. ${ }^{16}$ It is not clear why the fluid leaking from the perifoveal capillaries accumulates within the macula, despite the massive production and distribution of inflammatory cytokines throughout the retina. The reduced fluid reabsorption within the macula may be explained, at least in part, by the absence of blood vessels within the avascular zone combined with the high metabolic activity of the fovea. ${ }^{17}$ Patients with marked postoperative inflammation tend to develop PCME more frequently than others do. ${ }^{14}$ This observation implies that the degree of inflammation determines the severity of PCME, which can range from very mild to clinically significant forms. As postoperative inflammation is inseparably linked to each cataract surgery procedure, noncomplicated cases also induce an increase in subclinical central macular thickness (CMT). In a study by Perente et al, ${ }^{18}$ the CMT measured by using OCT increased significantly between 1 and 6 months postoperatively. The typical PCME OCT scans for different times after cataract surgery are shown in Figures 1-3. In the study conducted by Von Jagow et al, ${ }^{19}$ a moderate increase in macular thickness between the first and sixth week after surgery was observed, but there was no significant correlation between CMT and the best-corrected visual acuity (BCVA). Sahin et $\mathrm{al}^{20}$ reported that a moderate CMT increase in the first 3 postoperative months did not cause vision impairment in patients without PCME and that macular thickness gradually decreased to baseline values by the end of the 3-month period. Akcay et $\mathrm{al}^{21}$ observed higher macular thickness in patients after complicated cataract surgery than in those whose procedure had been uneventful.

\section{Increased risk of PCME}

Many local, systemic, and surgery-related conditions were shown to increase the risk of PCME (Table 2), among which diabetes was the most common. ${ }^{11,16,22-25}$ Recently, some of these risk factors, including diabetes, capsule rapture, previous diagnosis of epiretinal membrane, uveitis, retinal vein occlusion, and retinal detachment repair, were confirmed in a retrospective database study based on 81,984 surgeries. ${ }^{26}$ The same study showed that high myopia, age-related macular degeneration, or the use of a PG analog did not increase the risk of PCME and that the risk increased proportionally with increasing severity of diabetic retinopathy. Some of the methodology and findings of the study were, however, criticized. ${ }^{27}$

Singh et $\mathrm{al}^{28}$ published the results of a multicenter, randomized, double-masked, placebo-controlled study in 263 diabetic patients with nonproliferative diabetic retinopathy undergoing cataract surgery. The patients were randomized to receive nepafenac $0.1 \%$ or vehicle three times daily beginning on day 1 before the surgery through postoperative day 90. All patients also used prednisolone acetate 1.0\% four times daily for 2 weeks after surgery. The OCT scan performed on days 30 and 90 revealed macular edema in a significantly greater proportion of patients from the sham

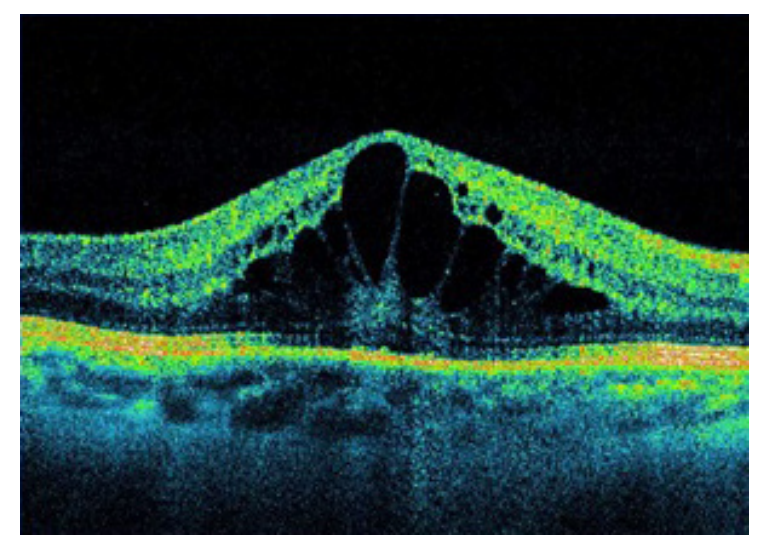

Figure I OCT 5 weeks after cataract surgery.

Note: Visual acuity $=0.4$.

Abbreviation: OCT, optical coherent tomography. 


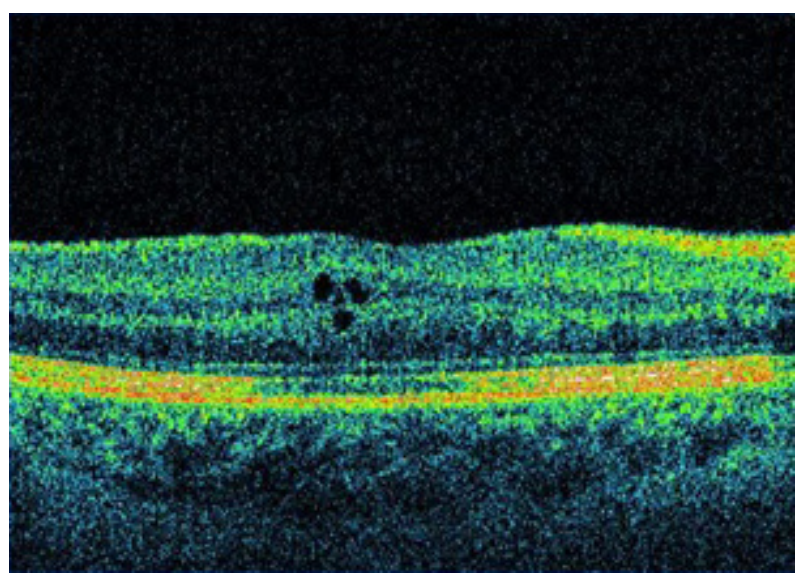

Figure 2 OCT 6 weeks after cataract surgery.

Abbreviation: OCT, optical coherent tomography.

treatment group than from the nepafenac group. The use of nepafenac also resulted in better visual acuity at all time points. However, the control eyes were treated with prednisolone acetate $1 \%$ for only 2 weeks after surgery, whereas the eyes from the nepafenac group received therapy lasting for more than 90 days, including day 1 preceding the surgery, which could have affected the study results. Henderson et $\mathrm{a}^{23}$ presented a retrospective analysis following resident-performed cataract surgery accompanied by preventive regimens based on either topical steroid alone, topical nonsteroidal anti-inflammatory drugs (NSAIDs) alone (diclofenac $0.1 \%$ or ketorolac tromethamine $0.5 \%$ for times daily), a combination of both, or neither. They found the rate of PCME development in patients with diabetes, posterior capsule tear, or vitreous loss who received topical NSAIDs for 3 months after cataract surgery to be similar to

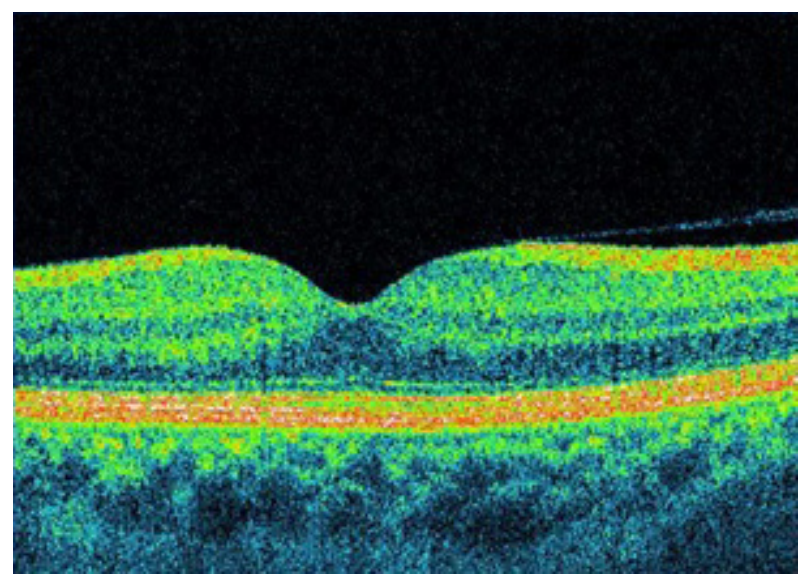

Figure 3 OCT 3 months after cataract surgery.

Note: Visual acuity $=1.0$.

Abbreviation: OCT, optical coherent tomography. that in low-risk patients. This result supports the preventive use of NSAIDs for the first 3 postoperative months following complicated cataract surgery, as well as for diabetic patients. Almeida et al, ${ }^{29}$ in an open-labeled nonmasked randomized study, compared ketorolac with placebo in high-risk patients with uveitis, diabetes, or macular disease after cataract surgery, observing a significantly decreased macular volume in patients receiving ketorolac. Therefore, they concluded that in high-risk patients, preventive use of topical NSAIDs is an effective and safe intervention to minimize postoperative macular edema. Meyer and Schönfeld ${ }^{30}$ presented a case report of PCME following complicated cataract surgery treated successfully with a $0.7-\mathrm{mg}$ dexamethasone intravitreal implant (Ozurdex) after three previous ineffective intravitreal injections of $0.4 \mathrm{mg}$ of dexamethasone.

\section{PCME treatment}

Modern cataract surgery is an efficient procedure and is generally associated with good visual results. However, despite recent surgical improvements, after PCME develops, postoperative vision can be suboptimal. To ensure a favorable outcome, one ought to know when and how to effectively treat this complication.

Treatment options correspond to many postulated mechanisms for the formation of PCME. Corticosteroids and topical NSAIDs, either as monotherapy or combined therapy, are a commonly used first-line treatment approach. ${ }^{31}$ When this approach is ineffective, intravitreal application of corticosteroids and anti-vascular endothelial growth factor agents may be an option. In eyes with chronic PCME and vitreomacular traction, pars plana vitrectomy can be considered. This topic is discussed extensively elsewhere. ${ }^{31}$

The role of corticosteroids in the treatment of PCME involves the inhibition of leukotriene and PG synthesis. ${ }^{32}$ Corticosteroids decrease PG production by inhibiting phospholipase A2 in the arachidonic acid cascade. In addition to their anti-inflammatory properties, corticosteroids also inhibit macrophage and neutrophil migration and decrease capillary permeability and vasodilation. ${ }^{33}$ They exert a broader antiinflammatory effect than do NSAIDs and have a much longer track record of use, which makes many ophthalmologists reluctant to substitute NSAIDs for corticosteroids as part of inflammation management after cataract surgery. Of note is that differences in concentration, lipophilicity, and innate glucocorticosteroid activity among individual corticosteroid formulations may change their anti-inflammatory effect within the eye. It is essential to accommodate these 
Table 2 Factors associated with an increased risk of PCME

\begin{tabular}{|c|c|c|}
\hline Systemic conditions & Ocular conditions & Surgery associated \\
\hline $\begin{array}{l}\text { Age (elderly, children) } \\
\text { Arteriosclerotic vascular disease, } \\
\text { including hypertension and diabetes }\end{array}$ & $\begin{array}{l}\text { Ocular inflammatory diseases } \\
\text { Retinal vascular diseases } \\
\text { Diabetic retinopathy and maculopathy } \\
\text { Choroidal neovascularization } \\
\text { Drug reactions, including topical epinephrine and epinephrine-like } \\
\text { drugs, prostaglandin analogs, and high oral doses of nicotinic acid } \\
\text { Retinal dystrophies, including retinitis pigmentosa and Goldmann- } \\
\text { Favre syndrome } \\
\text { Tractional maculopathies, including idiopathic epiretinal membranes } \\
\text { Retinal detachment and retinal detachment surgery } \\
\text { Intraocular tumors } \\
\text { Optic nerve head abnormalities, including optic pit, optic nerve } \\
\text { coloboma (typical and atypical), and morning glory disc anomaly } \\
\text { Penetrating keratoplasty } \\
\text { Vitreous surgery } \\
\text { Laser surgery } \\
\text { Cryotherapy and segmental buckling of retinal tears without } \\
\text { detachments }\end{array}$ & $\begin{array}{l}\text { Additional trauma during } \\
\text { surgery, especially to the iris } \\
\text { Posterior capsule rupture } \\
\text { Vitreous loss, vitreous traction } \\
\text { High phaco energy } \\
\text { Long duration of the surgery }\end{array}$ \\
\hline
\end{tabular}

Abbreviation: PCME, pseudophakic cystoid macular edema.

differences in order to properly interpret the therapeutic effect of comparative or combination treatment with NSAIDs.

NSAIDs work by inhibiting the COX enzymes. They are active in the inflammatory process, catalyzing the biosynthesis of eicosanoids from arachidonic acid to produce PGs and thromboxanes. ${ }^{33}$ PGs within the eye produce vasodilatation and disruption of the blood-ocular barrier. ${ }^{34}$ The main isoforms of COX are COX-1 and COX-2. COX-1 is a constitutive enzyme involved in the regulation of physiologic processes. COX-2 is an inducible enzyme, expressed primarily in inflammatory responses and in relation to pain or fever. ${ }^{34}$ The development of COX-2-selective NSAIDs was proposed to relieve pain and inflammation without the adverse effects of the COX-1 blockade. Several ophthalmic NSAID formulations are available on the market, each with individual properties. The advantages of NSAIDs over corticosteroids include good intraocular pressure control and stability, reduced risk of secondary infections, and additional analgesic effect. ${ }^{8,35,36}$ However, typically NSAIDs (except for celecoxib and diclofenac), in contrast to corticosteroids, do not inhibit lipoxygenase, and thus do not prevent the production of leukotrienes. Moreover, NSAIDs were shown to have anti-inflammatory and antiangiogenic effects independent of their inhibition of COX. Good evidence suggests that topical NSAIDs reduce postoperative inflammation after cataract surgery. ${ }^{34}$ It was argued that the greater therapeutic effect of NSAIDs plus corticosteroids is due to the additive rather than the synergistic effect of two antiinflammatory drugs. ${ }^{34}$
Shelsta and Jampol ${ }^{37}$ suggested a stepwise algorithm for PCME treatment. They recommended starting with the initial combination of a topical NSAID (less expensive variety) and a topical corticosteroid, and then considering a more expensive topical NSAID when there is no vision improvement after 4-6 weeks. For refractory cases, they proposed intravitreal corticosteroid injection. Benhamou et $\mathrm{al}^{38}$ administered repeated intravitreal triamcinolone injections to patients with refractory PCME who showed decreased macular thickness in OCT studies. Nevertheless, all patients had a recurrence of macular edema within 2-4 months. Bellocq et $\mathrm{al}^{39}$ assessed the effectiveness of intravitreal dexamethasone implants (Ozurdex) for treating PCME, mainly after cataract surgery that was refractory to first-line treatment (the EPISODIC study). They found that more than half of the patients who were followed-up for at least 1 year presented neither a functional nor an anatomical recurrence. In patients who received two injections, the effectiveness and safety of the two implants were similar. The same authors also studied the effectiveness of the dexamethasone implant in PCME in a larger sample of patients with longer follow-up (the EPISODIC-2 study). ${ }^{40}$ The results not only confirmed those obtained in the pilot study but also provided new information. Only the absence of PCME risk factors at diagnosis proved to be a good predictor of functional effectiveness, while the patient's age, type of surgery, initial visual acuity, naive status, and time of first injection did not constitute predictive factors for good response to treatment (defined as a gain of ten letters in BCVA during follow-up). Falavarjani et $\mathrm{al}^{41}$ 
reviewed the use of intravitreal bevacizumab injection for the treatment of PCME. They did not find any high-quality evidence to recommend anti-vascular endothelial growth factor agents as a routine treatment for PCME. However, they concluded that bevacizumab injection can be considered in patients with refractory PCME that is unresponsive to intravitreal steroids. Wu et $\mathrm{al}^{42}$ reported short-term structural and functional outcomes following intravitreal injection of infliximab in eyes with refractory PCME treated previously with topical nepafenac $0.1 \%$, topical prednisolone acetate $1 \%$, intravitreal triamcinolone (4 mg), and intravitreal bevacizumab (1.25 mg). Most patients experienced BCVA improvement by at least $\geq 3$ lines at the 6-month follow-up. BCVA deterioration was not reported in any case. Khurana et $\mathrm{a}^{43}$ have also shown a benefit of dexamethasone implants for patients with diabetes who develop PCME after cataract surgery. Harbour et $\mathrm{al}^{44}$ demonstrated a beneficial effect of pars plana vitrectomy in eyes with chronic PCME and vitreomacular traction.

\section{PCME prevention}

Prevention of PCME includes the least invasive surgery possible with no complications, short surgery time, and in some cases, the use of anti-inflammatory pharmacological agents. The latter subject is presently a topic of hot debate between those who advocate the standard use of NSAIDs in all cataract operations and those who advocate their use only in high-risk cases. Since many PCME cases are mild and resolve spontaneously, accurately estimating the therapeutic benefits of the available anti-inflammatory drugs is challenging. It is not easy to precisely determine the extent to which the preventive use of anti-inflammatory therapies may improve long-term visual outcomes. Therefore, the answer to the question about whether such treatment prevents chronic PCME or reduces its severity is not as obvious as it may initially seem. The differences in methodology between the studies assessing the efficacy of PCME prevention and treatment make this analysis even more difficult. Because macular edema can be diagnosed from clinical examination, fluorescein angiography, or OCT (Table 1), ${ }^{45-47}$ the diagnostic management of PCME directly affects the inclusion criteria for related clinical studies. As a result, some researchers investigate only clinically significant PCME, whereas others may study asymptomatic subclinical PCME as well. In addition, in some studies, patients were administered anti-inflammatory drugs preoperatively, which may have affected the evaluation of the efficacy of drugs used postoperatively. Furthermore, the compared substances differed in their ocular tissue penetration (eg, topical NSAIDs vs $0.1 \%$ fluorometholone, which has a limited intraocular penetration); hence, such studies may only approximate the efficacy of NSAIDs compared with placebo. ${ }^{47,48}$ Estimating the therapeutic benefits of NSAIDs is also not straightforward because most studies involve the concomitant use of corticosteroids. Moreover, the results of the studies can differ according to the proinflammatory potential of a given patient at baseline (preexisting uveitis or diabetes). One should also remember that since the incidence of PCME is very low, trials must have a proper sample size to find any statistically significant and clinically relevant differences. If the particular study cannot find a statistically significant difference, this does not always mean that the treatment is not effective.

Many studies assessing the effectiveness of NSAIDs in the perioperative period for the prevention of PCME in extracapsular and intracapsular cataract surgeries are of historical relevance today, and thus will not be presented here. We discuss the most recent and relevant studies in the following paragraphs.

Almeida et $\mathrm{al}^{47}$ in a prospective, placebo-controlled, parallel-assignment, double-masked, randomized clinical trial compared the effect of topical nepafenac $0.1 \%$, ketorolac $0.5 \%$, and placebo on PCME in patients after modern-day phacoemulsification surgery with posterior chamber intraocular lens implantation. The patients used one of the aforementioned substances four times daily for 4 weeks, starting 1 day before the planned surgery. In addition, all patients were administered prednisolone acetate $1.0 \%$ eyedrops four times daily over the first week postoperatively. The dose was then tapered by one drop every week. The OCT performed at baseline and at 4 weeks postoperatively did not show a significant retinal thickening in subjects treated with NSAIDs. While a mild CMT increase in placebo eyes was noted, at 4 weeks there was no significant difference in the ultimate visual acuity between the groups. The study concluded that in low-risk patients, the use of topical nepafenac or ketorolac does not seem to offer benefit over placebo in preventing OCT changes indicative of macular edema after surgery. Other authors found no significant differences between diclofenac $0.1 \%$ and ketorolac $0.45 \%$ groups in macular thickness 1 month after uneventful surgery. ${ }^{49}$ However, at the second postoperative month, the ketorolac group had significantly lower central subfield thickness than the diclofenac group. Wang et $\mathrm{al}^{50}$ compared the efficacy of bromfenac $0.1 \%$ administered twice daily for 4 weeks, bromfenac $0.1 \%$ administered twice daily for 8 weeks, fluorometholone 
$0.1 \%$ administered three times daily for 4 weeks, and dexamethasone $0.1 \%$ administered three times daily for 4 weeks. All patients also received $15 \mathrm{mg}$ of prednisone in one daily dose for 7 days postoperatively. No topical antiinflammatory drugs were used preoperatively. At 2 months, the mean OCT-based retinal thickness was significantly lower in both bromfenac groups. However, there were no significant differences in visual acuity between the groups. Wittpenn et al, ${ }^{51}$ in a randomized and masked comparison, reported a low incidence of OCT-confirmed PCME in low-risk patients treated with prednisolone acetate $1.0 \%$ in monotherapy and no difference in visual acuity if combined with ketorolac $0.4 \%$ (corticosteroid vs corticosteroid plus NSAID). Shorstein et $\mathrm{al}^{52}$ found, in turn, that adding a prophylactic NSAID to postoperative topical prednisolone acetate was associated with a reduced risk of acute macular edema with visual acuity of 20/40 or worse.

A randomized double-blind study showed that application of an anti-inflammatory drug for 3 days before surgery reduces PCME and improves vision in the short term, but there is no evidence that this practice affects long-term outcomes. ${ }^{53}$ Donnenfeld et $a l,{ }^{53}$ in a randomized doublemasked study, assessed the effect of different preoperative dosing regiments of ketorolac $0.4 \%$ on postoperative PCME and visual acuity. They randomized treated eyes to one of four groups: the eyes in the first group received ketorolac for 3 days before cataract surgery, in the second group for 1 day, and in the third group for 1 hour before cataract surgery, while the fourth group received placebo. Postoperatively, all three active treatment arms were administered ketorolac four times daily for 3 weeks, while the controls received placebo. In addition, all eyes were postoperatively administered topical prednisolone acetate $1.0 \%$ four times daily for 2 weeks followed by twice daily for 1 week. At 2 weeks, the eyes pretreated with ketorolac for 1 or 3 days had significantly better visual acuity than did the placebo eyes, but this effect was not sustained for up to 3 months. The results suggest that the use of NSAIDs for up to 3 days before surgery accelerates visual recovery in the immediate postoperative period, but it does not affect the ultimate visual outcomes at 3 months after surgery. In contrast, Tzelikis et al, ${ }^{54}$ in a prospective, placebocontrolled, randomized study, reported the inefficacy of ketorolac $0.4 \%$ and nepafenac $0.1 \%$ administered for 2 days before surgery and continued for 4 weeks postoperatively in OCT-assessed PCME prevention in eyes after uneventful cataract surgery, compared with placebo. They did not, however, compare preoperative prophylactic treatment with postoperative treatment alone.

\section{PREMED study}

The European Society of Cataract and Refractive Surgeons funded a 2-year, multicenter, double-blind randomized study, the Prevention of Macular Edema After Cataract Surgery (PREMED), which started recruiting patients in 2013 and is expected to provide evidence-based guidelines for PCME prevention and treatment after cataract surgery in patients without and with diabetes. ${ }^{55}$ In the nondiabetic population, the patients receive bromfenac $0.09 \%$ eye drops twice per day starting 2 days preoperatively and for 2 weeks postoperatively + dexamethasone $0.1 \%$ eye drops four times per day starting 2 days before surgery and continuing four times per day during the first postoperative week and one drop less per day every following week; or bromfenac $0.09 \%$ eye drops twice per day starting 2 days before surgery and for 2 weeks postoperatively; or dexamethasone $0.1 \%$ eyedrops for times per day starting 2 days before surgery and continuing for times per day during the first postoperative week and one drop less per day every following week. In patients with diabetes, there are four groups: 1) NSAID (bromfenac $0.09 \%$ ) + corticosteroid (dexamethasone $0.1 \%$ ) eyedrops; 2) NSAID + corticosteroid eyedrops + subconjunctival injection of $40 \mathrm{mg}$ triamcinolone acetonide perioperatively; 3) NSAID + corticosteroid eyedrops + intravitreal injection of $1.25 \mathrm{mg}$ bevacizumab perioperatively; and 4) NSAID + corticosteroid eyedrops + subconjunctival injection of $40 \mathrm{mg}$ triamcinolone acetonide $+1.25 \mathrm{mg}$ bevacizumab intravitreal perioperatively. ${ }^{55}$

\section{Recommendations}

No official US Food and Drug Administration (FDA)approved strategy for PCME prevention after cataract surgery is available, but an extensive meta-analysis of the literature in 1998 concluded that treatment with NSAIDs is beneficial. ${ }^{56}$ The next major review published in 2010 reported similar findings, emphasizing the lack of evidence of a long-term benefit in preventing PCME-induced vision loss. ${ }^{34} \mathrm{~A}$ Cochrane full systematic review assessing the effects of NSAIDs in the treatment of PCME after cataract surgery was reported in 2012. ${ }^{57}$ This review found two randomized controlled trials that showed that a topical NSAID $(0.5 \%$ ketorolac tromethamine ophthalmic solution) has a positive effect on chronic PCME and two randomized controlled trials that revealed no significant difference between comparative groups. The authors concluded that the effects of NSAIDs in acute and chronic PCME remain unclear and need further investigation. A recent systemic review and subsequent metaanalysis from 2014 found NSAIDs to be more effective than 
topical corticosteroids in preventing PCME.$^{58}$ However, this meta-analysis may be limited by the tendency of researchers and journals to publish studies with positive findings rather than those showing little or no effect. ${ }^{48}$

In 2015, the American Academy of Ophthalmology (AAO) published a literature review on the clinical efficacy and safety of using topical NSAIDs to prevent PCMEinduced vision loss after cataract surgery. ${ }^{48}$ The researchers retrieved 149 unique citations and selected 27 articles of possible clinical relevance for a full-text review. Of these 27 articles, 12 were deemed pertinent enough to be analyzed in full. They also identified two additional articles from the reference list of the selected articles and one conference presentation. The AAO Ophthalmic Technology Assessment Committee Retina/Vitreous Panel rated each selected citation according to the level of scientific evidence. The findings of the analysis were as follows: 1) NSAID therapy is effective in reducing PCME detected by angiography or OCT and may accelerate visual recovery after surgery when compared directly with placebo or topical corticosteroid formulations of limited intraocular penetration; 2) the use of NSAIDs does not alter the long-term ( $\geq 3$ months) visual outcomes; 3 ) there is no evidence that the benefits of NSAID therapy could not be obtained with equivalent dosing of a corticosteroid; and 4) the literature does not support a seemingly synergistic effect of using both a NSAID and a corticosteroid, which seems unlikely given the overlapping mechanisms of action of both drug groups. ${ }^{59}$ This analysis suggests that, although dosing of NSAIDs before surgery may accelerate visual recovery within the first several weeks after cataract surgery, there is no level I evidence to support the long-term (3 months or more) use of NSAIDs in preventing vision loss secondary to PCME after cataract surgery.

Another systematic review and meta-analysis evaluating the optimum medical strategy to prevent PCME after uncomplicated cataract surgery was also published in $2015 .^{60}$ The authors performed an extensive literature search, reviewed 161 full-text articles, and included 30 individual randomized clinical trials. They excluded studies investigating intracapsular or extracapsular cataract extraction. In nondiabetic patients, topical NSAIDs, compared with topical corticosteroids, were found to significantly reduce the odds of developing PCME. The study also demonstrated that a combination of topical NSAIDs and corticosteroids, compared with topical corticosteroids alone, significantly reduced the odds of developing PCME, whereas the combination treatment did not show any benefit over topical NSAIDs alone in an indirect treatment comparison. Therefore, the authors drew the conclusion that topical NSAIDs should always be part of the preventive treatment after cataract surgery in nondiabetic patients. In diabetic patients, the odds of developing PCME were significantly lower after topical combination treatment with NSAIDs and corticosteroids, compared with a single-drug treatment with topical corticosteroids. It was, however, pointed out that the review included studies of all PCME, regardless of whether or not it was associated with decreased vision, and that it provided no information to support the conclusion that NSAIDs are more effective than corticosteroids at reducing PCME. ${ }^{61}$

Guidelines of the Royal College of Ophthalmologists recommend the use of topical NSAIDs before and after surgery in patients at increased risk of PCME, eg, with diabetes, previous PCME, previous retinal vein occlusion, epiretinal membrane, and PG use. ${ }^{62}$ The Canadian Ophthalmological Society notes that prophylaxis with topical NSAIDs reduces the rate of early angiographic PCME, but this difference is not significant in long-term follow-up periods, and it is unknown whether prophylactic treatment with NSAIDs translates to a decrease in the development of late-onset PCME after the NSAIDs have been discontinued. ${ }^{63}$ Nevertheless, Canadian Ophthalmological Society concludes that steroids, NSAIDs, or both are recommended in the perioperative period ("Consensus"). ${ }^{63}$ The first-line therapy mandated by the French Society of Ophthalmology for symptomatic PCME is acetazolamide along with topical NSAIDs and corticosteroids. ${ }^{64}$

\section{Critical summary}

First, whereas most topical NSAID formulations are FDAapproved for preventing inflammation after cataract surgery, the FDA-approved time limit for such treatment is 14 days. Most topical NSAIDs are not approved for PCME prevention or treatment. ${ }^{47}$ Second, many studies focused on the reduction of angiography-based PCME as a primary end point, which is problematic because angiographic PCME does not show a strong correlation with visual acuity. ${ }^{2,45,65}$ In addition, there is no commonly accepted method of reporting OCT-based PCME, which hinders the assessment of treatment outcomes. ${ }^{28,49,50}$ Third, some studies may have favored NSAID treatment by preferential pretreatment with NSAIDs in one study arm..$^{28,45,47,51}$ In other studies, no adjustment was made for dosing disparities between groups treated with a corticosteroid alone and with the combination of a NSAID and a corticosteroid. ${ }^{51}$

An evaluation of the currently available published data does not define the optimum prevention of PCME, which still 
remains unclear and requires further investigation. Placebocontrolled, double-masked, randomized clinical trials are largely lacking. Nevertheless, all studies discussed herein provide clinical evidence that the use of an anti-inflammatory drug before surgery reduces PCME and improves vision in the short term. Current evidence does not suggest, however, that this management strategy affects long-term outcomes. ${ }^{48}$ Such prevention may prove particularly beneficial in highrisk patients. Therefore, it is essential to perform the correct preoperative evaluation of patients in order to classify them as normal or high-risk cataract patients.

\section{Disclosure}

The authors report no conflicts of interest in this work.

\section{References}

1. Bradford JD, Wilkinson CP, Bradford RH Jr. Cystoid macular edema following extracapsular cataract extraction and posterior chamber intraocular lens implantation. Retina. 1988;8(3):161-164.

2. Mentes J, Erakgun T, Afrashi F, Kerci G. Incidence of cystoid macular edema after uncomplicated phacoemulsification. Ophthalmologica. 2003;217(6):408-412.

3. Wetzig PC, Thatcher DB, Christiansen JM. The intracapsular versus the extracapsular cataract technique in relationship to retinal problems. Trans Am Ophthalmol Soc. 1979;77:339-347.

4. Levitz L, Reich J, Roberts TV, Lawless M. Incidence of cystoid macular edema: femtosecond laser-assisted cataract surgery versus manual cataract surgery. J Cataract Refract Surg. 2015;41(3):683-686.

5. Yoshioka H, Kawashima K, Sugita T. [Cystoid macular edema following cataract extraction 2]. Nippon Ganka Gakkai Zasshi. 1972;76: $1118-1124$.

6. Solomon LD. Efficacy of topical flurbiprofen and indomethacin in preventing pseudophakic cystoid macular edema. Flurbiprofen-CME Study Group I. J Cataract Refract Surg. 1995;21(1):73-81.

7. Warren KA, Fox JE. Topical nepafenac as an alternate treatment for cystoid macular edema in steroid responsive patients. Retina. 2008; 28(10):1427-1434.

8. Wright PL, Wilkinson CP, Balyeat HD, Popham J, Reinke M. Angiographic cystoid macular edema after posterior chamber lens implantation. Arch Ophthalmol. 1988;106(6):740-744.

9. Miyake K, Masuda K, Shirato S, et al. Comparison of diclofenac and fluorometholone in preventing cystoid macular edema after small incision cataract surgery: a multicentered prospective trial. Jpn J Ophthalmol. 2000;44(1):58-67.

10. Ching HY, Wong AC, Wong CC, Woo DC, Chan CW. Cystoid macular oedema and changes in retinal thickness after phacoemulsification with optical coherence tomography. Eye (Lond). 2006;20(3):297-303.

11. Lobo CL, Faria PM, Soares MA, Bernardes RC, Cunha-Vaz JG. Macular alterations after small-incision cataract surgery. J Cataract Refract Surg. 2004;30(4):752-760.

12. Gass JD, Norton EW. Cystoid macular edema and papilledema following cataract extraction. A fluorescein fundoscopic and angiographic study. Arch Ophthalmol. 1966;76(5):646-661.

13. Schubert HD. Cystoid macular edema: the apparent role of mechanical factors. Prog Clin Biol Res. 1989;312:277-291.

14. Ursell PG, Spalton DJ, Whitcup SM, Nussenblatt RB. Cystoid macular edema after phacoemulsification: relationship to blood-aqueous barrier damage and visual acuity. J Cataract Refract Surg. 1999;25: 1492-1497.

15. Hudes GR, Li WY, Rockey JH, White P. Prostacyclin is the major prostaglandin synthesized by bovine retinal capillary pericytes in culture. Invest Ophthalmol Vis Sci. 1988;29:1511-1516.
16. Flach AJ. The incidence, pathogenesis and treatment of cystoid macular edema following cataract surgery. Trans Am Ophthalmol Soc. 1998;96: 557-634.

17. Tsilimbaris MK, Tsika C, Diakonis V, Karavitaki A, Pallikaris I. Macular edema and cataract surgery, in cataract surgery. In: Zaid F, editor. Cataract Surgery. InTech. 2013: ISBN 978-953-51-0975-4.

18. Perente I, Utine CA, Ozturker C, et al. Evaluation of macular changes after uncomplicated phacoemulsification surgery by optical coherence tomography. Curr Eye Res. 2007;32(3):241-247.

19. von Jagow B, Ohrloff C, Kohnen T. Macular thickness after uneventful cataract surgery determined by optical coherence tomography. Graefes Arch Clin Exp Ophthalmol. 2007;245(12):1765-1771.

20. Sahin M, Cingu AK, Gozum N. Evaluation of cystoid macular edema using optical coherence tomography and fundus autofluorescence after uncomplicated phacoemulsification surgery. J Ophthalmol. 2013;2013: 376013.

21. Akcay BI, Bozkurt TK, Guney E, et al. Quantitative analysis of macular thickness following uneventful and complicated cataract surgery. Clin Ophthalmol. 2012;6:1507-1511.

22. Johnson MW. Etiology and treatment of macular edema. Am J Ophthalmol. 2009;147(1):11-21.e1.

23. Henderson BA, Kim JY, Ament CS, Ferrufino-Ponce ZK, Grabowska A, Cremers SL. Clinical pseudophakic cystoid macular edema. Risk factors for development and duration after treatment. J Cataract Refract Surg. 2007;33(9):1550-1558.

24. Benitah NR, Arroyo JG. Pseudophakic cystoid macular edema. Int Ophthalmol Clin. 2010;50(1):139-153.

25. Yonekawa Y, Kim IK. Pseudophakic cystoid macular edema. Curr Opin Ophthalmol. 2012;23(1):26-32.

26. Chu CJ, Johnston RL, Buscombe C, et al. Risk factors and incidence of macular edema after cataract surgery: a database study of 81984 eyes. Ophthalmology. 2016;123(2):316-323.

27. Grzybowski A, Kim SJ. Corticosteroids substituted by nonsteroidal antiinflammatory drugs: is it justified by evidence-based medicine? $J$ Cataract Refract Surg. 2016;42(3):510-511.

28. Singh R, Alpern L, Jaffe GJ, et al. Evaluation of nepafenac in prevention of macular edema following cataract surgery in patients with diabetic retinopathy. Clin Ophthalmol. 2012;6:1259-1269.

29. Almeida DR, Johnson D, Hollands H, et al. Effect of prophylactic nonsteroidal antiinflammatory drugs on cystoid macular edema assessed using optical coherence tomography quantification of total macular volume after cataract surgery. J Cataract Refract Surg. 2008;34(1): 64-69.

30. Meyer LM, Schönfeld CL. Cystoid macular edema after complicated cataract surgery resolved by an intravitreal dexamethasone $0.7-\mathrm{mg}$ implant. Case Rep Ophthalmol. 2011;2(3):319-322.

31. Guo S, Patel S, Baumrind B, et al. Management of pseudophakic cystoid macular edema. Surv Ophthalmol. 2015;60:123-137.

32. Conway MD, Canakis C, Livir-Rallatos C, Peyman GA. Intravitreal triamcinolone acetonide for refractory chronic pseudophakic cystoid macular edema. J Cataract Refract Surg. 2003;29(1):27-33.

33. Simone JN, Whitacre MM. Effects of anti-inflammatory drugs following cataract extraction. Curr Opin Ophthalmol. 2001;12(1):63-67.

34. Kim SJ, Flach AJ, Jampol LM. Nonsteroidal anti-inflammatory drugs in ophthalmology. Surv Ophthalmol. 2010;55(2):108-133.

35. Roberts CW, Brennan KM. A comparison of topical diclofenac with prednisolone for postcataract inflammation. Arch Ophthalmol. 1995; 113(6):725-727.

36. Rossetti L, Bujtar E, Castoldi D, Torrazza C, Orzalesi N. Effectiveness of diclofenac eyedrops in reducing inflammation and the incidence of cystoid macular edema after cataract surgery. J Cataract Refract Surg. 1996;22(Suppl 1):794-749.

37. Shelsta HN, Jampol LM. Pharmacologic therapy of pseudophakic cystoid macular edema: 2010 update. Retina. 2011;31(1):4-12.

38. Benhamou N, Massin P, Haouchine B, Audren F, Tadayoni R, Gaudric A. Intravitreal triamcinolone for refractory pseudophakic macular edema. Am J Ophthalmol. 2003;135(2):246-249. 
39. Bellocq D, Korobelnik JF, Burillon C, et al. Effectiveness and safety of dexamethasone implants for post-surgical macular oedema including Irvine-Gass syndrome: the EPISODIC study. Br J Ophthalmol. 2015; 99(7):979-983.

40. Bellocq D, Pierre-Kahn V, Matonti F, et al. Effectiveness and safety of dexamethasone implants for postsurgical macular oedema including Irvine-Gass syndrome: the EPISODIC-2 study. Br J Ophthalmol. 2016.

41. Falavarjani GK, Parvaresh MM, Modarres M, Hashemi M, Samiy N. Intravitreal bevacizumab for pseudophakic cystoid macular edema; a systematic review. J Ophthalmic Vis Res. 2012;7(3):235-239.

42. Wu L, Arevalo JF, Hernandez-Bogantes E, Roca JA. Intravitreal infliximab for refractory pseudophakic cystoid macular edema: results of the Pan-American Collaborative Retina Study Group. Int Ophthalmol. 2012;32(3):235-243.

43. Khurana RN, Palmer JD, Porco TC, Wieland MR. Dexamethasone intravitreal implant for pseudophakic cystoid macular edema in patients with diabetes. Ophthalmic Surg Lasers Imaging Retina. 2015;46(1): 56-61.

44. Harbour JW, Smiddy WE, Rubsamen PE, Murray TG, Davis JL, Flynn HW Jr. Pars plana vitrectomy for chronic pseudophakic cystoid macular edema. Am J Ophthalmol. 1995;120(3):302-307.

45. Kraff MC, Sanders DR, Jampol LM, Peyman GA, Lieberman HL. Prophylaxis of pseudophakic cystoid macular edema with topical indomethacin. Ophthalmology. 1982;89(8):885-890.

46. Miyake K, Ota I, Miyake G, Numaga J. Nepafenac $0.1 \%$ versus fluorometholone $0.1 \%$ for preventing cystoid macular edema after cataract surgery. J Cataract Refract Surg. 2011;37(9):1581-1588.

47. Almeida DR, Khan Z, Xing L, et al. Prophylactic nepafenac and ketorolac versus placebo in preventing postoperative macular edema after uneventful phacoemulsification. J Cataract Refract Surg. 2012; 38(9):1537-1543.

48. Kim SJ, Schoenberger SD, Thorne JE, Ehlers JP, Yeh S, Bakri SJ. Topical nonsteroidal anti-inflammatory drugs and cataract surgery: a report by the American Academy of Ophthalmology. Ophthalmology. 2015;122(11):2159-2168

49. Lee TH, Choi W, Ji YS, Yoon KC. Comparison of ketorolac $0.45 \%$ versus diclofenac $0.1 \%$ for macular thickness and volume after uncomplicated cataract surgery. Acta Ophthalmol. 2016;94(3):e177-e182.

50. Wang QW, Yao $\mathrm{K}, \mathrm{Xu} \mathrm{W}$, et al. Bromfenac sodium $0.1 \%$, fluorometholone $0.1 \%$ and dexamethasone $0.1 \%$ for control of ocular inflammation and prevention of cystoid macular edema after phacoemulsification. Ophthalmologica. 2013;229(4):187-194.

51. Wittpenn JR, Silverstein S, Heier J, et al. A randomized, masked comparison of topical ketorolac $0.4 \%$ plus steroid vs steroid alone in low-risk cataract surgery patients. Am J Ophthalmol. 2008;146(4): 554-560.

52. Shorstein NH, Liu L, Waxman MD, Herrinton LJ. Comparative effectiveness of three prophylactic strategies to prevent clinical macular edema after phacoemulsification surgery. Ophthalmology. 2015;122(12): $2450-2456$.
53. Donnenfeld ED, Perry HD, Wittpenn JR, Solomon R, Nattis A, Chou T. Preoperative ketorolac tromethamine $0.4 \%$ in phacoemulsification outcomes: pharmacokinetic-response curve. J Cataract Refract Surg. 2006;32(9):1474-1482.

54. Tzelikis PF, Vieira M, Hida WT, et al. Comparison of ketorolac $0.4 \%$ and nepafenac $0.1 \%$ for the prevention of cystoid macular oedema after phacoemulsification: prospective placebo-controlled randomised study. Br J Ophthalmol. 2015;99(5):654-658.

55. European Society of Cataract and Refractive Surgeons; Maastricht University Medical Center. In: ClinicalTrials.gov. Bethesda, MD: National Library of Medicine (US); 2000. Available from: https://clinicaltrials. gov/ct2/show/NCT01774474. NLM Identifier: NCT01774474. Accessed October 25, 2015.

56. Rossetti L, Chaudhuri J, Dickersin K. Medical prophylaxis and treatment of cystoid macular edema after cataract surgery. The results of a meta-analysis. Ophthalmology. 1998;105(3):397-405.

57. Sivaprasad S, Bunce C, Crosby-Nwaobi R. Non-steroidal antiinflammatory agents for treating cystoid macular oedema following cataract surgery. Cochrane Database Syst Rev. 2012;(2):CD004239.

58. Kessel L, Tendal B, Jorgensen KJ, et al. Post-cataract prevention of inflammation and macular edema by steroid and nonsteroidal antiinflammatory eye drops: a systematic review. Ophthalmology. 2014; 121(10):1915-1924.

59. Schoenberger SD, Kim SJ. Nonsteroidal anti-inflammatory drugs for retinal disease. Int J Inflam. 2013;2013:281981.

60. Wielders LH, Lambermont VA, Schouten JS, et al. Prevention of cystoid macular edema after cataract surgery in nondiabetic and diabetic patients: a systematic review and meta-analysis. Am JOphthalmol. 2015; 160(5):968-981.e33.

61. Kim SJ, Jampel H. Prevention of cystoid macular edema after cataract surgery in non-diabetic and diabetic patients: a systematic review and meta-analysis. Am J Ophthalmol. 2016;161:221-222.

62. The Royal College of Ophthalmologists. Cataract Surgery Guidelines. London: USDTRCoO-Aahwr; 2010.

63. Canadian Ophthalmological Society Cataract Surgery Clinical Practice Guideline Expert Committee. Canadian Ophthalmological Society evidence-based clinical practice guidelines for cataract surgery in the adult eye. Can J Ophthalmol. 2008;43(Suppl 1):S7-S57.

64. Daien V, Papinaud L, Domerg C, Lacombe S, Daures JP, Vilain M. Incidence and characteristics of cystoid macular edema after cataract surgery. Ophthalmology. 2016;123:663-664.

65. Nussenblatt RB, Kaufman SC, Palestine AG, Davis MD, Ferris FL 3rd Macular thickening and visual acuity. Measurement in patients with cystoid macular edema. Ophthalmology. 1987;94(9):1134-1139.
Clinical Interventions in Aging

\section{Publish your work in this journal}

Clinical Interventions in Aging is an international, peer-reviewed journal focusing on evidence-based reports on the value or lack thereof of treatments intended to prevent or delay the onset of maladaptive correlates of aging in human beings. This journal is indexed on PubMed Central, MedLine,
CAS, Scopus and the Elsevier Bibliographic databases. The manuscript management system is completely online and includes a very quick and fair peer-review system, which is all easy to use. Visit http://www.dovepress. com/testimonials.php to read real quotes from published authors. 